\title{
Technological Scheme of Complex Peat Processing for Obtaining of Multifunctional Hydrophobic and Hydrophilic Powders
}

\author{
Oleg Misnikov ${ }^{1, *}$ \\ ${ }^{1}$ Tver State Technical University, A. Nikitin Street, 22, 170026, Tver, Russia
}

\begin{abstract}
The method of hydrophobic modification of dispersed materials is based on the extraction of bituminous components of peat and applying them to a treated surface. The industrial implementation of this method is possible in the following main directions. First, it is the thermochemical treatment in a reactor of the entire material volume by hydrophobic components of peat with a low concentration. Second, it is the obtaining of concentrated hydrophobically-modifying compositions and their use in the production technology of various types of powdered dispersed materials. Positive results were obtained with organo-mineral hydrophobicallymodifying concentrates based on peat with clinker, kaolin, chalk, lime, vermiculite. Third, it is the use of the sorption properties of the porous structure of peat to saturate it with additional hydrophobic components: bitumen, oleic acid, organosilicon compounds, etc. The main advantage of the obtained composite hydrophobic modifiers is quality (accurate) dosing. There are promising directions of the use of hydrophobically-modifying additives in the construction industry, chemical industry and to ensure fire safety. A block diagram of the technological process of complex peat processing to produce hydrophobic and hydrophilic powders is proposed. Additional processing of production wastes allows for the production of a stabilizing additive for asphalt concrete.
\end{abstract}

\section{Introduction}

The foundation of a new scientific direction of hydrophobic modification of mineral dispersed materials with the bituminous components of peat was laid with the theoretical and experimental studies on the hydrophobic treatment of Portland cement with the products of thermochemical destruction of peat. The scientific principles underlying the production of hydrophobic cement make it possible to apply them to other types of dispersed materials. This allows a significant expansion in the use of peat processing products.

The initial main scientific task was to develop such a method that would allow the creation of continuous film coatings on mineral grains of cement from bitumen and thermal bitumen extracted from peat organic matter [1]. In this case, the modified cement becomes resistant to the exposure of droplet fluid and vaporous moisture. This task was successfully

\footnotetext{
* Correspondent author: oleg.misnikov@,gmail.com
} 
solved. However, the developed method at the present stage of technological development is practically not applicable in the industrial production of cement. In this regard, other alternatives were proposed based on its partial use at certain stages of the technological process (for example, mixed grinding of components). Later, the studies [2, 3] demonstrated the possibility of hydrophobic treatment of other mineral dispersed materials, which are subject to caking due to the appearance of different types of interactions between the particles [4].

Presently, the development of the hydrophobic modification method is possible in the following main areas:

- direct thermochemical treatment of the entire volume of the mineral material with hydrophobic components of peat with a low concentration in the low-temperature pyrolysis reactor [1];

- obtaining concentrated hydrophobic-modifying compositions with their subsequent application during the production of various types of powdered disperse materials [2];

- use of the sorption properties $[5,6]$ of the porous peat structure to saturate it with additional hydrophobic components.

The results of the studies show [7] that the first of the above areas can be implemented in the industrial production of gypsum binders. This follows from the analysis of parameters of the technological process of the production, namely: temperature, time and air conditions of the furnace in which the gypsum is fired. Moreover, this approach does not increase the cost of the process, since the cost of the peat semi-finished product introduced into gypsum is comparable to the cost of the powder of calcium sulfate dihydrate (gypsum) itself. It has been experimentally established [7], that if optimal concentrations $(0,5-1 \%)$ of the peat additive are maintained, the resulting hydrophobically-modified gypsum binder completely retains its qualitative characteristics. But at the same time, it additionally acquires hydrophobic properties, which increase its shelf life without loss of activity (strength).

The second direction is based on obtaining organic mineral concentrates (the content of the organic component can reach more than $20 \%$ ) from the mineral "carrier" and peat. One of the components is used as a mineral carrier, which subsequently does not affect the quality indicators of the processed material (at least), or improves them (at most). To date, studies have been conducted with organomineral hydrophobically-modifying concentrates (HMC) based on Portland cement, kaolin and chalk [2, 8]. They were used for hydrophobic treatment of cement (by the method of mixed grinding of the concentrate, clinker and gypsum) [2], as well as for various types of mineral fertilizers and powdered butadienenitrile rubber [8] (dusting method). The effectiveness of using such concentrates varied. The greatest effectiveness was achieved when processing rubber with chalk-based HMC. The processed experimental samples retained their flowability during storage under the pressure of $14.2 \mathrm{KPa}$, temperature $20-25^{\circ} \mathrm{C}$ and relative air humidity of $70-80 \%$ during one month. Among mineral fertilizers, carbamide powdered with the additive shows the best storage characteristics, although the method is also applicable to other types of hygroscopic granules.

And, finally, the third direction seems to be the most promising: the production and subsequent use of hydrophobically-modifying additives (HMA). Characteristics of the porous structure of peat particles [9-11] make it possible to saturate the system with various types of traditional hydrophobic agents: bitumen [12], oleic acid, organosilicon compounds, etc. $[13,14]$. This peat-based powder retains its flowability at sufficiently high concentrations of water repellents (experimentally confirmed the concentration of up to $20 \%$ ). At the same time, the use of mineral particles for these purposes is limited by their low sorption capacity. In them, sorption occurs mainly in the surface layer, while in peat 
the predominant for saturation with hydrophobic agents is the volumetric mechanism of liquid absorption [14].

The main advantage of the obtained HMA is quality (precise) dosing, which makes it possible to use them in almost any kind of mixing and (or) grinding equipment. Moreover, as the expert community becomes familiar with the proposed hydrophobic treatment methods, new ideas for their use in other areas of science and technology emerge.

Therefore, the purpose of the work is to create a basic technological scheme (a prototype of industrial technology) for the production of powdered hydrophobicallymodifying organic and organomineral materials. Besides, during its development it is necessary to pay close attention to the use of production wastes in the technological process. According to preliminary estimates, the amount of industrial waste can reach more than $50 \%$ of the total amount of used raw materials for some types of peat.

\section{Results and Discussion}

The fundamental technological scheme of the HMA production process takes into account all currently known initial conditions and features of application of the developed scientific principles, methods and approaches for the production of hydrophilic and hydrophobic powders based on peat (Figure). Peat raw material is extracted, as a rule, by a milling method [15], which allows reducing the moisture content of peat $(w)$ in the field to $w=35$ $45 \%$. However, it is possible to use other technologies for the development of peat deposits as well, including those that have less negative impact on the environment $[16,17]$.

In order to increase the economic sustainability of the technology, it is necessary to follow the concept of producing different types of products using approximately the same set of equipment. As the main equipment it is planned to use a dryer [18] (to reduce the humidity of the initial peat to $16-25 \%$ ), a ball mill, a reactor for low-temperature thermal treatment of materials and a set of equipment for enrichment of peat additives with additional hydrophobic components $[13,14]$.

The market for hydrophobic modifiers for various dispersed materials may now be limited for both objective and subjective reasons. For this reason, powdered peat-humic fertilizers as well as sodium or potassium ballast-containing humates can be produced as an initial product in demand. They are recommended to be used for organic agriculture, improvement of soil fertility, combating desertification of territories, solving problems on environment protection and other directions [19-24]. For this purpose, pre-dried ( $w=16-$ $25 \%$ ) peat is sent for fine grinding to a ball mill. A complex of mineral fertilizers and/or alkali, depending on the type of product, is fed into the ball mill through a dosing system. The mixed grinding of components forms powder that is homogeneous in particle size composition, due to the destruction of large particles and the uniform distribution (and partial binding) of mineral elements (nitrogen, phosphorus, potassium) and alkali ( $\mathrm{NaOH}$, $\mathrm{KOH})$ in the volume of organic material (peat).

For the production of hydrophobically-modifying additives and concentrates, pre-dried peat is milled. Ball mills or other grinding equipment can also be used for this purpose, including those installed in some types of peat dryers (e.g. shaft-mill dryers). After grinding, the peat powder is sent to screening to separate the target fraction (particle size less than $100 \mu \mathrm{m}$ ) and organic waste (particle size greater than $100 \mu \mathrm{m}$ ). The practice of conducting the mechanical screening process on an experimental vibratory screen shows that the ratio between the target fraction and waste is approximately 50:50\%.

Peat powder with a particle size of less than 100 microns is a hydrophobic semi-finished product for the production of gypsum binders, since the main parameters (temperature, time, the presence of an oxidizing agent, etc.) of gypsum firing technology [7] correspond to the main parameters of the hydrophobic modification process [1]. The experiments on 
firing calcium sulfate dihydrate (gypsum) with peat hydrophobic agents at a temperature of $\mathrm{T}=180-200^{\circ} \mathrm{C}$ completely confirm this assumption.

The optimization of the quantitative composition of the powder of calcium sulfate dihydrate (99-99.5\%) and peat additives (0.5-1\%) made it possible to obtain a hydrophobically-modified gypsum binder (hemihydrate gypsum) with a low sorption capacity for water vapor and brand strength [7]. The estimated cost of the hydrophobic semi-finished product approximately corresponds to the cost of gypsum powder. There is no need in any major changes in the technological line for gypsum binder production. Therefore, no increase in the production cost of hydrophobically-modified gypsum binder (with a significant improvement in quality characteristics) is expected.

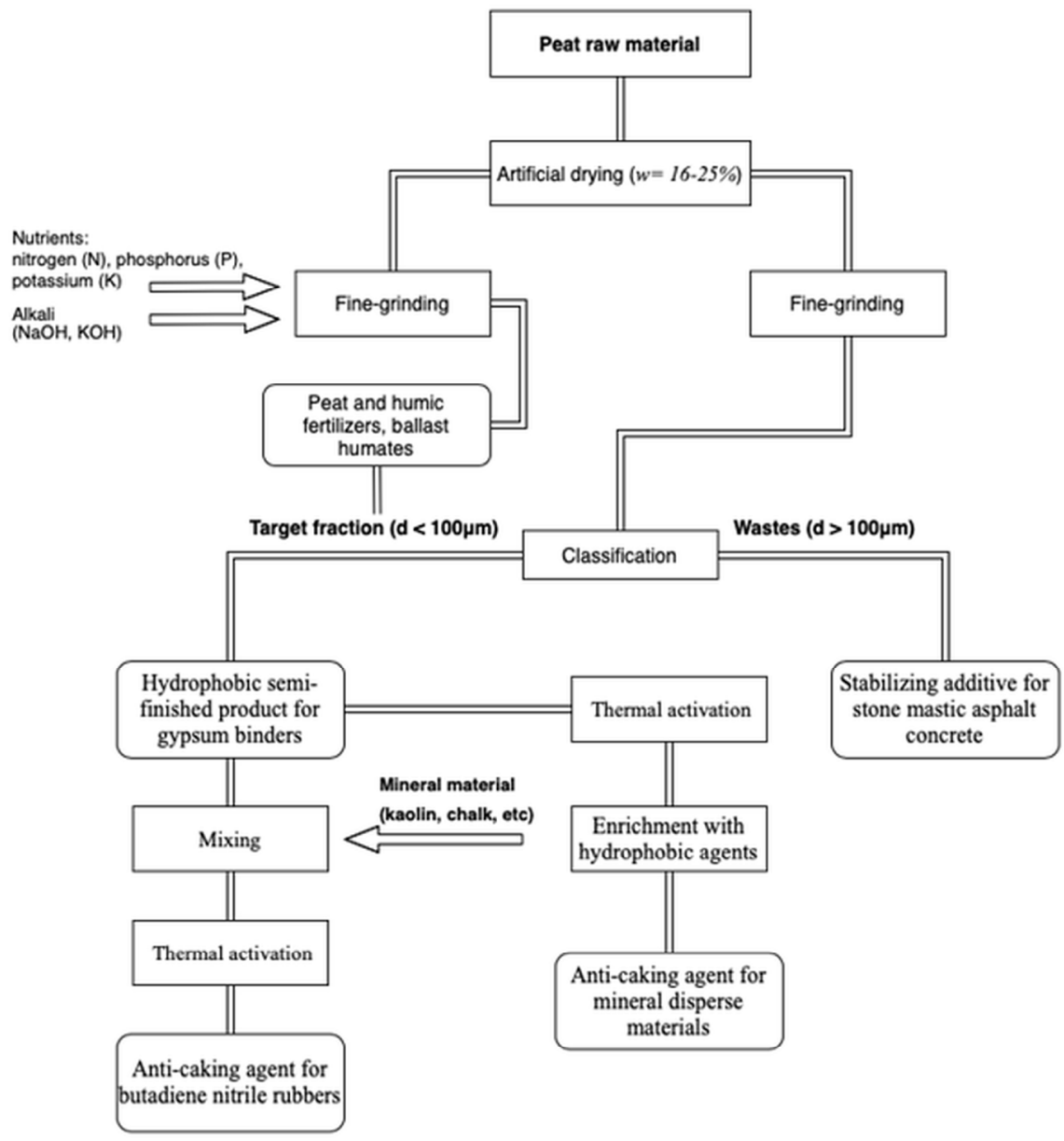

Fig. 1. Scheme of technological process of peat complex processing with obtaining hydrophobicallymodifying additives (explained in the text).

Thus, it is possible to market a hydrophobic semi-finished product for enterprises engaged in the production of gypsum binders, as well as its further processing to produce organic or organomineral HMA. When using such additives for treatment of powdered (or granulated) butadiene nitrile rubbers it is reasonable to use one of the components of raw mixtures as a mineral carrier for further vulcanization. Chalk or kaolin are often used as fillers in such mixtures. They increase mechanical durability, resistance to wear and abrasion, and also improve other physical characteristics of elastomer. In addition, due to 
reduction of rubber consumption in the mixture, the cost of the final product is also reduced. In addition, the reduction of rubber in the mixture decreases the cost of the final product as well. The paper [8] provides the concentration ranges of HMA based on chalk and kaolin, as well as some technological parameters of their production. However for successful industrial implementation of research results it is necessary to develop a special reactor for thermal activation of organic and organomineral mixtures. It is also possible to use (or upgrade) ready technological equipment from peat processing industries (dryers, mixers, extractors) and other industries (ball mill).

Approximately the same types of equipment are recommended for heat treatment of semi-finished peat product before its enrichment with additional hydrophobic agents. This principle helps to produce a hydrophobic powdered anti-caking agent for mineral dispersed materials: dry building mixtures, cement, fire extinguishing powders. The potential features of the developed anti-caking agents allow us to predict their use in other unexplored areas as well.

The technological scheme pays great attention to the use of production wastes (particles larger than 100 microns). The waste is dominated by peat particles with a high content of cellulose and lignin. Such material has been found to be a good stabilizing additive for stone mastic asphalt concrete $[25,26]$. The fibrous particles are homogeneous and do not contain bundles, aggregations of uncrushed material or foreign inclusions. In terms of physical and mechanical properties, this product has the following characteristics: average humidity does not exceed $8 \%$, it retains thermal stability under the impact of $220^{\circ} \mathrm{C}$ temperature and contains at least $80 \%$ of the fibers with length from 0.1 to $2 \mathrm{~mm}$. It is capable of sorbing and holding bitumen at technological temperatures, without having a negative impact on the binder and the mixture. The justification of the suitability of stabilizing additives from various types of peat and their optimal content in the asphalt mixture needs to be determined empirically.

\section{Conclusion}

The proposed technological scheme is the basis for the development of a comprehensive technology for thermochemical processing of peat with the production of several new products: peat humic fertilizers and ballast-containing humates, hydrophobic semi-finished product for gypsum binders, anti-caking additives for butadiene nitrile rubbers, extinguishing powders and other mineral disperse materials. The combination with additional processing of organic waste from industrial production will ensure economic stability and investment attractiveness when using the developed technology.

\section{References}

1. O. Misnikov, Mires and Peat, 18:22, 1-15 (2016)

2. O. Misnikov, Polymer Science. Series D, 7:3, 252-259 (2014)

3. O. Misnikov, O. Dmitriev, E. Chertkova, Eurasian Mining. Gornyi Zhurnal, 2:24, 30-34 (2015)

4. N. Gamayunov, S. Gamayunov, Eurasian Soil Science, 38:3, 297-304 (2005)

5. V. Lyadinskaya, S. Lin, A. Michailov, A. Povolotskiy, Langmuir, 32:50, 13435-13445 (2016)

6. A. Rizzuti, C. Newkirk, K. Wilson, L. Cosme, A. Cohen, Mires and Peat, 19:4, 1-10 (2017)

7. O. Misnikov, Mires and Peat, 21:7, 1-14 (2018) 
8. O. Misnikov, I. Korolev, Polymer Science. Series D, 10:3, 255-259 (2017)

9. I. Lishtvan, A. Orlov, S. Selyanina, T. Sokolova, N. Sosnovskaya, M. Trufanova, O. Yarygina, Solid Fuel Chemistry, 52:4, 211-216 (2018)

10. I. Sokolova, K. Skobtsova, L. Naumova, J. Slizhov, S. Selyanina, A. Orlov, IOP Conference Series: Earth and Environmental Science, 201:1, 012022 (2018)

11. V.Lebedev, O.Puhova, E3S Web of Conferences, 41, 01049 (2018)

12. E. Yurkevich, E. Dolidovich, P. Bel'kevich, L. Sheremet, S. Drozdovskaya, Solid Fuel Chemistry, 21:3, 15-17 (1987)

13. Z. Qu, F. Wang, P. Lui, Q. Yu, H. Brouwers, Materials and Structures, 53:30 (2020)

14. V.Belyakov, A.Kuporova, E3S Web of Conferences, 105, 01005 (2019)

15. P. Tcvetkov, Mires and Peat, 19:14, 1-12 (2017)

16. E. Kremcheev, D. Nagornov, Ecology, Environment and Conservation, 23:2, 956-965 (2017)

17. E. Kremcheev, D. Nagornov, Life Science Journal, 11:11, 453-456 (2014)

18. V.Lebedev, O.Puhova, E3S Web of Conferences, 15, 01018 (2017)

19. I. Lishtvan, Y. Yanuta, A. Abramets, V. Strigutskii, Y. Navosha, Solid Fuel Chemistry, 47:3, 147-152 (2013)

20. I. Lishtvan, V. Mulyarchik, A. Tomson, B. Kurzo, G. Naumova, N. Zhmakova, T. Tsaryuk, T. Sokolova, N. Makarova, T. Ovchinnikova, N. Sosnovskaya, V. Pekhtereva, L. Kalilets, Solid Fuel Chemistry, 51:5, 286-295 (2017)

21. G. Rabinovich, N. Kovalev, Yu. Smirnova, Sel'skokhozyaistvennaya Biologiya, 50:5, 665-672 (2015)

22. G. Rabinovich, N. Fomicheva, Indian Journal of Agricultural Research, 52:2, 182-186 (2018)

23. N. Kovalev, I. Baranovskii, Eurasian Soil Science, 33:1, 25-29 (2000)

24. Kosolapova, V. Yamaltdinova, E. Mitrofanova, D. Fomin, I. Teterlev, Bulgarian Journal of Agricultural Science, 22:6, 921-926 (2016)

25. Y. Kovalev, S. Budnichenko, Science \& Technique, 5, 55-58 (2012)

26. Y. Kovalev, Science \& Technique, 15:6, 451-459 (2016) 